九州大学学術情報リポジトリ

Kyushu University Institutional Repository

\title{
Note on Steady-state Approximation of Enzyme Kinetics
}

Aso, Yoichi

Laboratory of Sericultural Chemistry, Faculty of Agriculture, Kyushu University

Koga, Daizo

Laboratory of Sericultural Chemistry, Faculty of Agriculture, Kyushu University

Hayashi, Katsuya

Laboratory of Sericultural Chemistry, Faculty of Agriculture, Kyushu University

https://doi.org/10.5109/22875

出版情報：九州大学大学院農学研究院紀要. 19 (2/3)，pp. 125-138，1975-03. Kyushu University バージョン：

権利関係 : 


\title{
N ote on Steady-state Approximation of Enzyme Kinetics
}

\author{
Masahiro Okamoto, Yoichi Aso, Daizo Koga and Katsuya Hayashi \\ Laboratory of Sericultural Chemistry, Faculty of \\ Agriculture, Kyushu University, Fukuoka
}

(Received December 24, 1974)

\begin{abstract}
Recently, it has been gradually believed that enzymatic reactions generally involve several enzyme-substrate complexes in their pathways. For such the reactions, an approximation technique, for instance, steady-state approximation or Michaelis-Menten approximation, may not be simply applied to analyze the experimental data. In the present study, a three-step scheme of enzymatic reaction was subjected as a typical example of enzymatic reaction to the digital computer simulation to establish the practical experimental conditions which allow the proper application of approximation technique in handling the experimental data.
\end{abstract}

\section{INTRODUCTION}

It has been well recognized that the deterministic rate equation of enzymatic reaction has the form of simultaneous nonlinear differential equation, and some mathematical skillful tasks are required for obtaining the analytical solution of the rate equation. On the practical kinetics for enzymatic reactions, therefore, a suitable approximation technique such as steady-state approximation has been generally adopted to avoid the mathematical difficulties. The application of approximation technique will depend upon the experimental conditions which had been used for measurement of the behavior of the reaction. The rate parameters such as $K_{\mathrm{m}}$ or $V_{\max }$ calculated by the approximation technique may provide meaningless values and conduct one's judgement to erroneous direction unless the experimental conditions were properly assembled.

The limitation on the use of such an approximation technique had been clearly revealed by several investigators for only the case of relatively simple enzymatic reaction as typically represented by Michaelis-Menten scheme :

$$
\mathrm{E}+\mathrm{S} \rightleftharpoons \mathrm{ES} \rightarrow \mathrm{E}+\mathrm{P}
$$

In recent years, it came to know that general enzymatic reactions involve a sequence of the enzyme-substrate complexes as shown by following equation:

$$
\mathrm{E}+\mathrm{S} \rightleftharpoons \mathrm{ES}, \rightleftharpoons \mathrm{ES}, \rightleftharpoons \cdots \cdots \cdots \mathrm{ES}, \rightarrow \mathrm{E}+\mathrm{P}
$$

Thus, the progress of enzyme chemistry enabled the description of detailed parts of the enzymatic reaction scheme. Now, enzymatic reactions are discussed in the submolecular level. Contrary to the above situation, practical kinetic analyses seem to be performed frequently with ignoring the fine mechanisms of enzymatic reactions ; in practical experiments, the data on complicated reaction are simply delt 
with approximation technique by assuming rather simple reaction scheme without regard to the limitations of the approximation techniques.

Walter et al. (1964) have clarified the limitations on the application of the steady-state approximation for three-step enzymatic reaction by means of analog computer simulation. However, rate constants assumed in the simulation, that control the rates of formation and isomerization of enzyme-substrate complexes, were quite different from those observed on the real enzymatic reactions. Heineken et al. (1967 a, 1967 b) studied further the behaviors of three-step enzymatic reaction. However, the results did not seem to give clear information for the establishment of the practical experimental conditions.

The present study was designed to clarify the experimental conditions for enzymatic reaction that allow the application of the steady-state approximation on the analysis of enzymatic reaction involving the several enzyme-substrate complexes. The authors set up the three-step enzymatic reaction:

$$
\mathrm{E}+\mathrm{S} \rightleftharpoons \mathrm{ES}_{1} \rightleftharpoons \mathrm{ES}_{2} \rightarrow \mathrm{E}+\mathrm{P}
$$

and the behaviors of this reaction were simulated by digital computer in real time scale. The rate constants were suitably chosen with referring to those observed on the real enzymatic reactions.

\section{COMPUTATION}

The three-step reaction scheme may be represented by following equation (scheme) :

$$
\mathrm{E}+\mathrm{S} \underset{k_{-1}}{\stackrel{k_{+1}}{\rightleftarrows}} \mathrm{ES}_{1} \underset{k_{-2}}{\stackrel{k_{+2}}{\rightleftarrows}} \mathrm{ES}_{2} \stackrel{k_{+3}}{\longrightarrow} \mathrm{E}+\mathrm{P}
$$

where $\mathrm{E}, \mathrm{S}, \mathrm{ES}$ and $\mathrm{P}$ represent the enzyme, substrate, enzyme-substrate complex and the product, $k_{+1}$ and $k_{-1}$ are the constants for the formation of the complex ES,, $k_{+2}$ and $k_{-2}$ are for the isomerization of ES, to ES, and $k_{3}$ for the formation of the product. $E(t), S(t), X_{1}(t), X_{2}(t)$ and $\mathrm{P}(\mathrm{t})$ represent the concentrations of enzyme, substrate, $\mathrm{ES}_{1}, \mathrm{ES}$, and product respectively, at the reaction time t. $E(O), S(O), X,(O), X_{2}(0)$ and $\mathrm{P}(9)$ are the initial concentrations of the reaction species.

The rate equation of the three-step reaction scheme in form of simultaneous differential equation may be written as:

$$
\left\{\begin{array}{l}
\frac{d E(t)}{d t}=-k_{+1} \cdot E(t) \cdot S(t)+k_{-1} \cdot X_{1}(t)+k_{+3} \cdot X_{2}(t) \\
\frac{d S(t)}{d t}=-k_{+1} \cdot E(t) \cdot S(t)+k_{-1} \cdot X_{1}(t) \\
\frac{d X_{1}(t)}{d t}=k_{+1} \cdot E(t) \cdot S(t)-\left(k_{-1}+k_{+2}\right) \cdot X_{1}(t)+k_{2} \cdot X_{2}(t) \\
\frac{d X_{2}(t)}{d t}=k_{+2} \cdot X_{1}(t)-\left(k_{-2}+k_{+3}\right) \cdot X_{2}(t)
\end{array}\right.
$$




$$
\frac{d P(t)}{d t}=k_{+3} \cdot X_{2}(t)
$$

Since $E(t) \leq E(0), S(t) \leq S(0), X_{1}(t) \leq E(0), X_{2}(t) \leq E(0)$, and $P(t) \leq S(0)$, the concentrations in the rate equation were converted into the relative value. Then the equation (2) may be replaced by equation (3):

$$
\left\{\begin{array}{l}
\frac{d E^{\prime}(t)}{d t}=-k_{+1} S(0) \cdot E^{\prime}(t) \cdot S^{\prime}(t)+k_{-1} \cdot X_{1}^{\prime}(t)+k_{+3} X_{2}^{\prime}(t) \\
\frac{d S^{\prime}(t)}{d t}=-k_{+1} E(0) \cdot E^{\prime}(t) \cdot S^{\prime}(t)+k_{-1} \frac{E(0)}{S(0)} X_{1}^{\prime}(t) \\
\frac{d X_{1}^{\prime}(t)}{d t}=k+, S(O) \cdot E^{\prime}(t) \cdot S^{\prime}(t)-\left(k_{-1}+k_{+2}\right) X_{1}^{\prime}(t)+k_{-2} X_{2}^{\prime}(t) \\
\frac{d X_{2}^{\prime}(t)}{d t}=k_{+2} X_{1}^{\prime}(t)-\left(k_{-2}+k_{+3}\right) X_{2}^{\prime}(t) \\
\frac{d P^{\prime}(t)}{d t}=k_{+3} \frac{E(0)}{S(0)} X_{2}^{\prime}(t)
\end{array}\right.
$$

where

$$
\begin{aligned}
& E^{\prime}(t)=E(t) / E(0) \\
& S^{\prime}(t)=S(t) / S(O), \\
& X_{1}^{\prime}(t)=X_{1}(t) / E(O) \\
& X_{2}{ }^{\prime}(t)=X_{2}(t) / E(0) \\
& P^{\prime}(t)=P(t) / S(0)
\end{aligned}
$$

On the simulation, the initial concentrations were assumed as ;

$$
\begin{aligned}
& E(0)=1.0 \times 10^{-6} \mathrm{M} . \\
& \mathrm{S}(0)=a \times E(0) \\
& X_{1}(0)=X_{2}(0)=P(0)=0
\end{aligned}
$$

where $a$ is a fixed number $(a=10,20$, 100).

The values of rate constants were chosen as,

$$
\begin{aligned}
& 10^{4}<k_{+1}<10^{6}\left(\mathrm{M}^{-1} \mathrm{sec}^{-1}\right), \quad 1<k_{-1}<10\left(\mathrm{sec}^{-1}\right) \\
& 10^{3}<k_{+2}<10^{4}\left(\mathrm{sec}^{-1}\right), 10<k_{-2}<10^{2}\left(\mathrm{sec}^{-1}\right) \\
& 0<k_{+3}<0.2\left(\mathrm{sec}^{-1}\right)
\end{aligned}
$$

These values were chosen with referring to the experimentally obtained values on enzymatic reaction of lysozyme (Sykes, 1969 a; Holler et al., 1969; Chipman, 1971) and chymotrypsin (Sykes, 1969 b).

The numerical solution of the simultaneous differential equation was obtained by MRKGM subprogram. The maximum initial pitch in solving the differential equation was $0.06 \mathrm{sec}$. The MRKGM is a minor modification of SRKGD that is the FACOM SSL program for the numerical calculation of differential equation (Runge-Kutta-Gill method). When an overflow occurs at an operational register of computer during the calculation (a), and when the solutions (calculated values of concentration) are negative (b), the pitch is reduced to one-fifth of $t$ he original one and the calculation is repeated (recalculation) by this revised sub- 


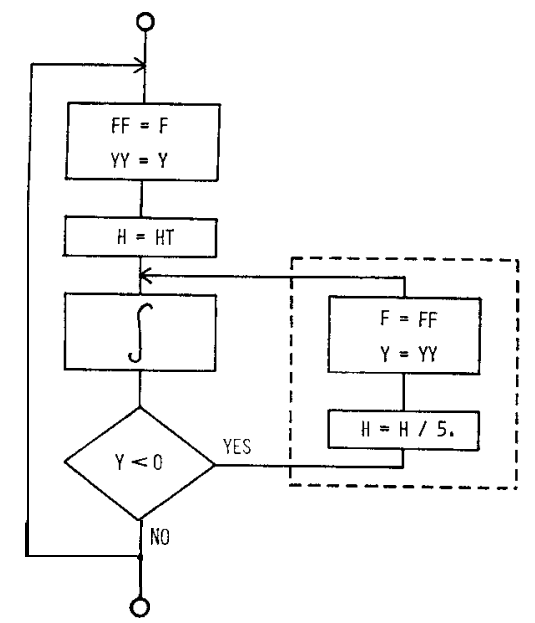

Fig. 1. Flow chart for avoiding obstruction in computation of differential equation (part of MRKGM).

program MRKGM. The flow chart of re-calculation part is shown in Fig. I. F and $\mathrm{Y}$ are differential value and integrated value (solution) respectively, FF and $\mathrm{YY}$ are memories to reserve the values of $\mathrm{F}$ and $\mathrm{Y}$ calculated before the occurrence of the obstruction ((a) or (b)), respectively. $H$ is the corrected pitch and HT is the initial pitch. Symbol $\int$ represents the operation by which the simultaneous differential equation is solved.

The program MRKGM has an advantage of that the obstruction caused by a wrong selection of the initial pitch can be avoided. Therefore, this program seems to be one of the simple and available programs of setting an unfeasibility caused by the exceedingly great difference between rate constants contained in the same simultaneous equation.

On the three-step enzymatic reaction, $d X_{1}(t) / d t=0$ and $d X_{2}(t) / d t=0$ are the essential conditions for the steady-state of the reaction. In practical reaction, the steady-state in the mathematical definition will not be attained, even if the reaction takes place under the most complete conditions. In the present study, however, it was assumed for convenience that the steady-state is attained when the trajectory of $X_{2}(t)$ with respect to the reaction time $t$ is visibly judged to be parallel to the horizontal axis. Since the calculated values of $X$, ( $t)$ contain the computational errors to some extent that are due to its very small value, it was not used for the judgement of the steady-state. Furthermore, the time periods in which the steady-state approximation could be adopted is defined as that in which the values of $X_{2}(t)$ deviate only $5 \%$ up- or downward from the linear trajectory. This time periods is called steady-state time and the time ratio is difined by the percent ratio of steady-state time to the entire reaction time.

All computations were performed by FACOM 230-75 Digital Computer and some FACOM SSL in the Computer Center, Kyushu University. 


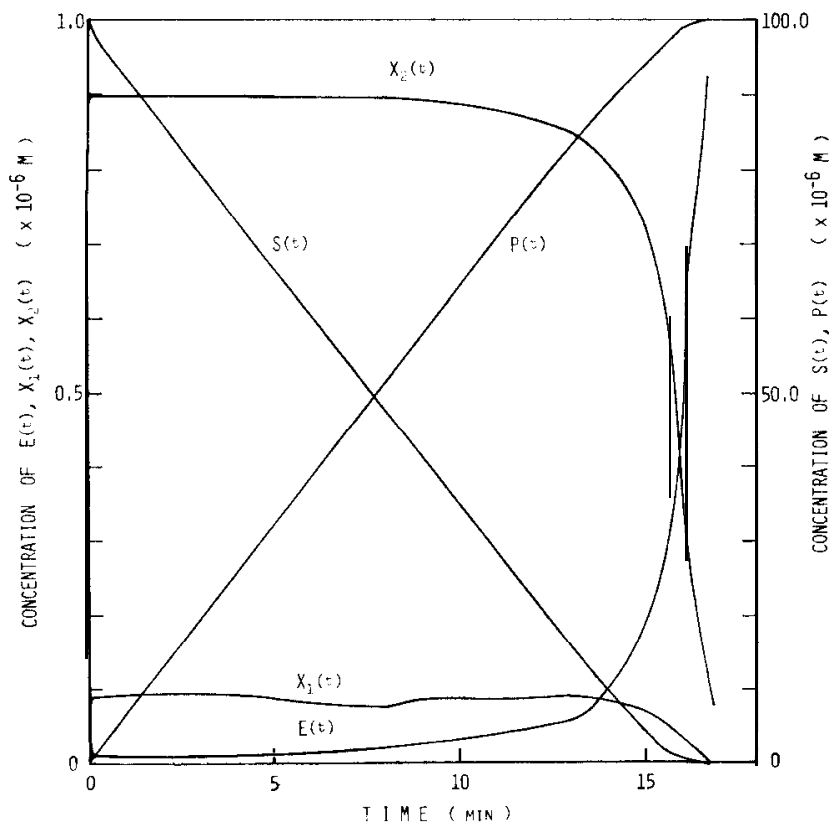

Fig. 2. Calculated time-courses of enzymatic reaction with scheme (1). Rate constants used for simulation are: $k_{+1}=5 \times 10^{5} \mathrm{M}^{-1} \mathrm{sec}^{-1}, k_{-1}=5 \mathrm{sec}^{-1}, k_{+2}=10^{3} \mathrm{sec}^{-1}, k_{-2}=10^{2}$ $\sec ^{-1}, k_{+3}=0.12 \mathrm{sec}^{-1}$. Molar ratio of $\boldsymbol{S}(0) / E(0)$ is assumed to be 100 .

\section{RESULTS}

\section{Relation between $\boldsymbol{k}_{+3}$ and steady-state}

A typical calculated time-course of three-step enzymatic reaction is shown in Fig. 2. The concentration of ES, was held in nearly constant value in the time periods from $0.1 \mathrm{sec}$ to $8 \mathrm{~min}$. A considerably irregular shape of $X_{1}(t)$ was due to the errors in the computation. The changes in $\boldsymbol{S}(t)$ and $\boldsymbol{P}(t)$ exhibit the linearity until $13 \mathrm{~min}$ of the reaction time where about $85 \%$ of the substrate had been converted to the product. The time-ratio on steady-state approximation defined before was roughly estimated to be $74 \%$.

The value of $k_{+3}$ controls the overall rate of the enzymatic reaction. The change in the $k_{+3}$ value under the fixing of the other rate constants did not affect the time-ratio as shown in Table 1.

Table 1. Effect of $\boldsymbol{k}_{+3}$ value on time ratio.

\begin{tabular}{cc}
\hline$k_{+3}\left(\sec ^{-1}\right)$ & Time ratio (\%) \\
\hline 0.12 & 74 \\
0.16 & 73 \\
0.20 & 75 \\
\hline
\end{tabular}

A typical example in the case where the steady-state was not attained is shown in Fig. 3. All the rate constants except for $\boldsymbol{k}_{+3}$ were common for Figs. 2 


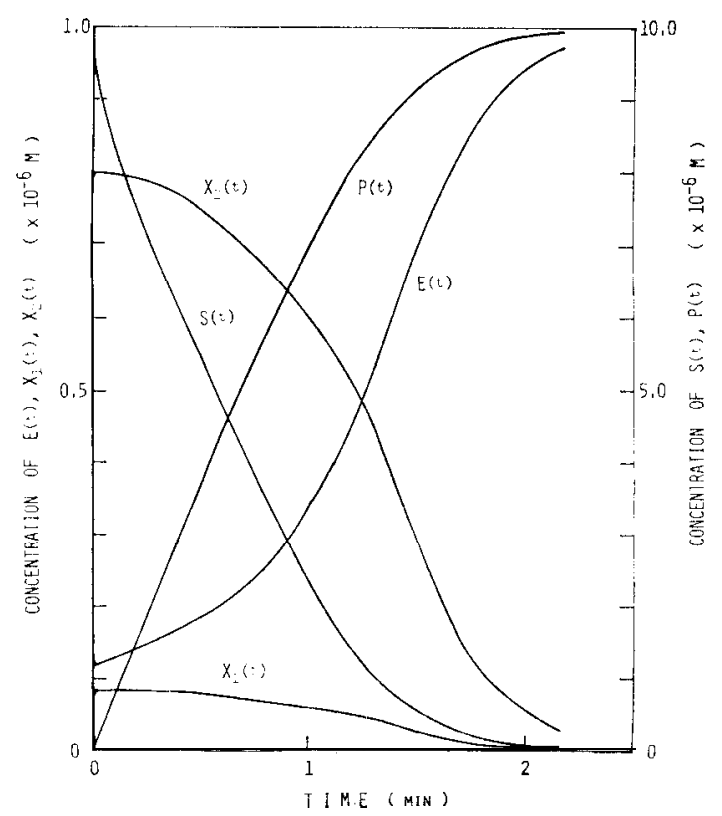

Fig. 3. Calculated time-courses of the reaction with scheme (1). Rate constants are : $k_{i 1}=5 \times 10^{5} \mathrm{M}^{-1} \mathrm{sec}^{-1}, k_{-1}=5 \mathrm{sec}^{-1}, k_{+2}=10^{3} \mathrm{sec}^{-1}, k_{-2}=10^{2} \mathrm{sec}^{-1}, k_{+3}=0.16 \mathrm{sec}^{-1}$. Molar ratio of $S(0) / E(0)$ is assumed to be 10 .

and 3 . In the case of Fig. $3, S(0) / E(0)$ was assumed to be 10 , differing from that for Fig. 2.

The decrease in the $k_{+3}$ value in legend of Fig. 3 did not lead to the appearance of steady-state as shown in Fig. 4 ; the time-course on $X$, $(t)$ with $k_{+3}=0.16 \mathrm{sec}^{-1}$ is simply extended along the time axis. Thus, the value of $k_{+3}$ does not correlate to the appearance of steady-state or the time-ratio.

\section{$\boldsymbol{S}(\boldsymbol{0}) / \boldsymbol{E}(\boldsymbol{0})$ Ratio and steady-state}

It is obvious from the time-courses of $X_{2}(t)$ shown in Figs. 2 and 3 that the $S(0) / E(0)$ ratio plays the vital role in the appearance of the steady-state in the enzymatic reaction. The time-courses of $X_{2}(t)$ with changing the $S(0) / E(0)$ ratio are shown in Fig. 5. The values of rate constants used for the calculation we re $k_{+1}=5 \times 10^{5} \mathrm{M}^{-1} \mathrm{sec}^{-1}, k_{-1}=5 \mathrm{sec}^{-1}, k_{+2}=10^{3} \mathrm{sec}^{-1}, k_{-2}=10^{2} \mathrm{sec}^{-1}, k_{+3}=0.16$ sec $^{-1}$. The estimated time-ratios from the curves in Fig. 5 are listed in Table 2. It is necessary for the application of the steady-state approximation to choose the $S(0) / E(0)$ ratio of more than 50. Fig. 6 shows the time-courses drawn by elongation of time axis of rapid enzymatic reaction with smaller $S(0) / E(0)$ ratios up to the unity (relative time). For the reaction with $\boldsymbol{S}(0) / E(0)$ ratio of 30 , early one-third periods may allow the application of the steady-state approximation, if one may expect a considerably large calculation error.

\section{Rate constants at first step and steady-state}

The effect of the $k_{i 1}$ value on the appearance of steady-state is shown in 


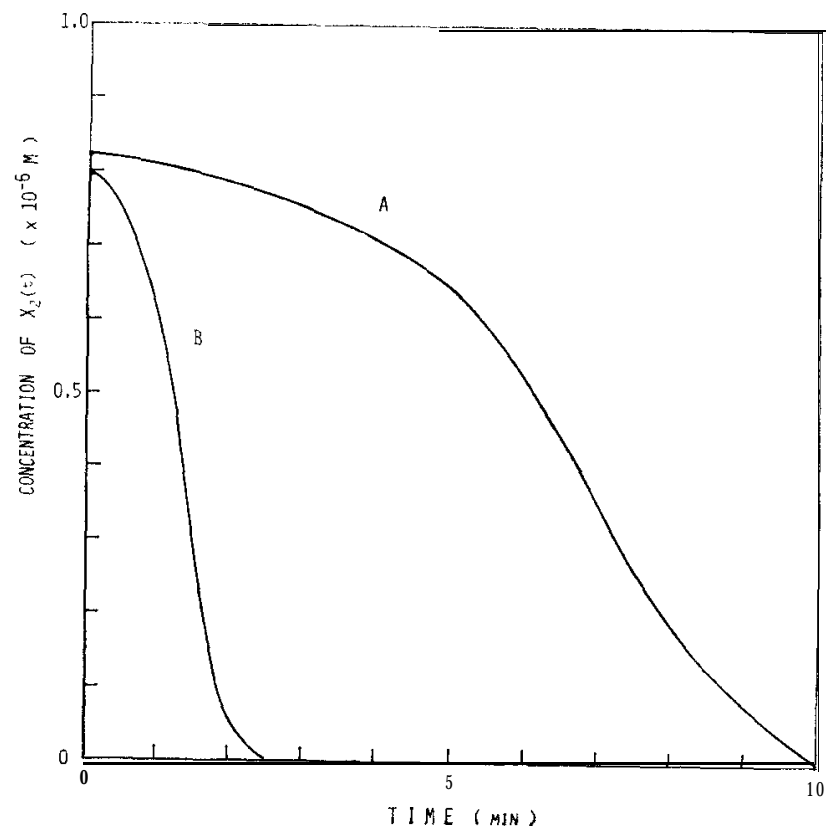

Fig. 4. Calculated time-courses of $X_{2}(t)$. Curve A; $k_{+3}=0.03 \mathrm{sec}^{-1}$. Curve B; $k_{+3}=0.16$ sec $^{-1}$. Other parameters are the same as Fig. 3.

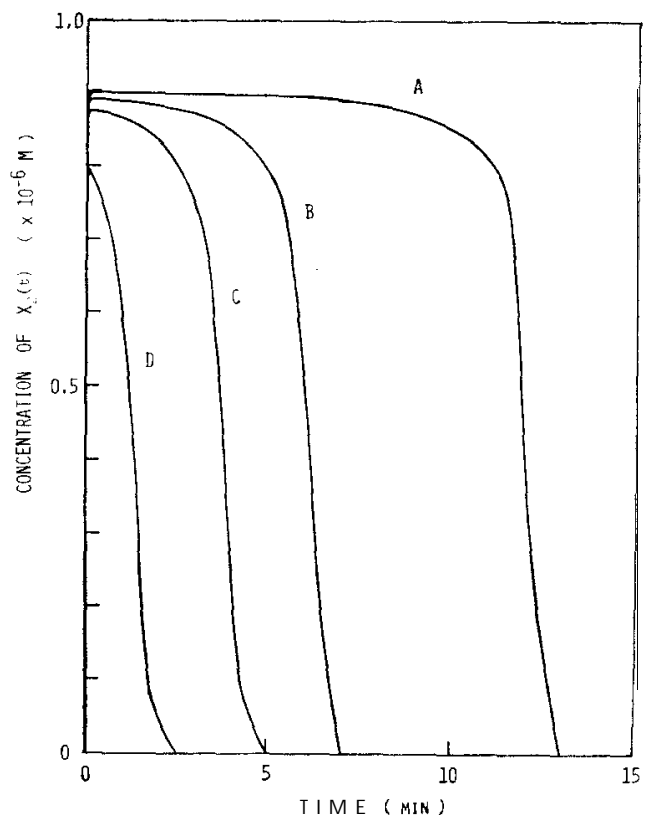

Fig. 5. Calculated time-courses of $X_{2}(t)$ with changing the $S(0) / E(0)$ ratio. Curve A ; $S(0) / E(0)=100$. Curve B $S(0) / E(0)=50$. Curve C; $S(0) / E(0)=30$. Curve D ; $S(0) / E(0)=10$. 
Table 2. Relation between $\boldsymbol{S}(\boldsymbol{O}) / \boldsymbol{E}(\boldsymbol{O})$ ratio and steady-state.

\begin{tabular}{cc}
$S(\boldsymbol{O}) / \boldsymbol{E}(\boldsymbol{O})$ & Time ratio $(\%)$ \\
\cline { 3 - 3 } & 73 \\
50 & 57 \\
30 & 0 \\
10 & 0 \\
\hline
\end{tabular}

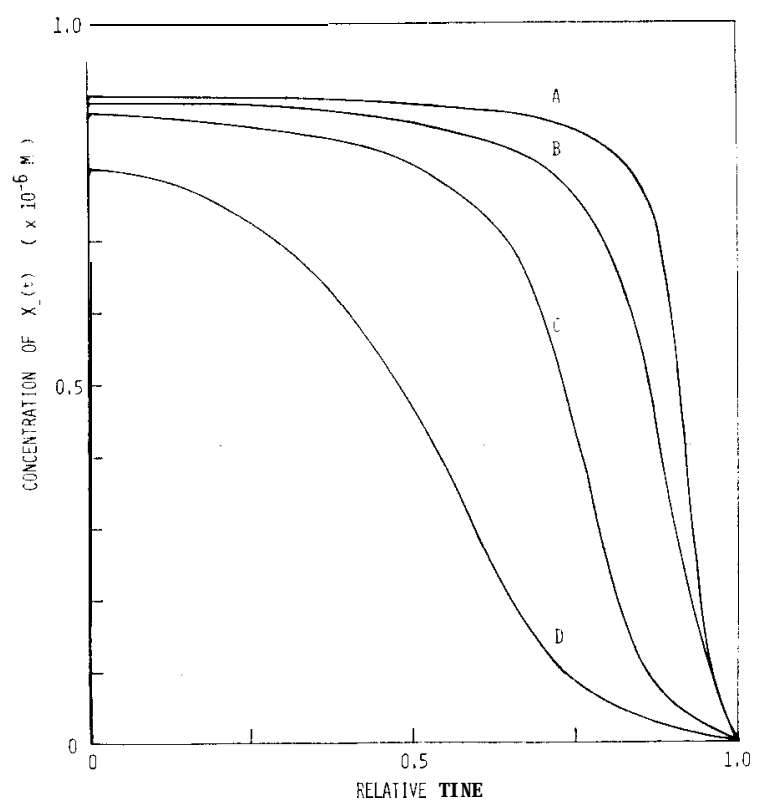

Fig. 6. Time-course of $\mathrm{X}$,(t) drawn by elongation of time axis in Fig. 5. Time axis shows the relative scale (the end of reaction time is assumed to be 1.0). Curve A; $S(0) / E(0)=-100$. Curve B; $S(0) / E(0)=50$. Curve C; $S(0) / E(0)=30$. Curve D; $S(0) /$ $E(0)=10$.

Fig. 7. For the calculation of the curves in the figure, the other rate constants we re fixed at $k_{1}=5 \mathrm{sec}^{-1}, k_{+2}=10^{3} \mathrm{sec}^{-1}, k_{-2}=10^{2} \mathrm{sec}^{-1}, k_{+3}=0.16 \mathrm{sec}^{-1}$ and the $S(0) / E(0)$ ratio of 50 was used. The estimated time-ratios are listed in Table 3. Thus, it is clear that the $k_{+1}$ value controls remarkably the periods of steadystate. However, the degree of change in the steady-state with changing the $k_{+1}$ value depends upon the original value of $k_{+1}$; as shown in Fig 7 , the changes in the $k_{+1}$ value from $5 \times 10^{6}$ to $5 \times 10^{5}$ and from $5 \times 10^{5}$ to $5 \times 10^{4}$, cause a quite different changes in the time-course of $X_{2}(t)$. This will be due to the nonlinearity of the rate equation. In this connection, the contribution of the combination of $k_{r 1}$ and $k_{\cdots_{1}}$ to the steady-state under fixing the values of the equilibrium constant $K_{1}$ to $10^{5}$ was estimated. As shown in Fig. 8 and Table4, the combination of forward and reverse rate constants in the equilibrium step seems to affect the steady-state behavior. It is clear from the comparison of the lowest 


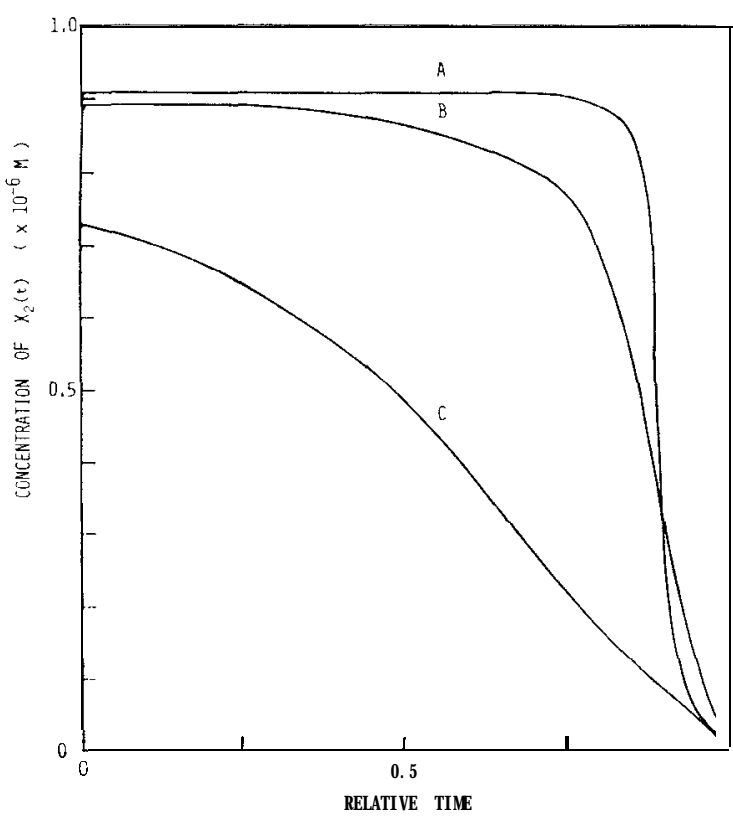

Fig. 7. Calculated time-courses of $X_{2}(t)$ with changing the $k_{+1}$ value (time axis shows the relative scale). Curve A; $k_{+1}=5 \times 10^{6} \mathrm{M}^{-1} \mathrm{sec}^{-1}$. Curve $\mathrm{B} ; k_{+1}=5 \times 10^{5} \mathrm{M}^{-1} \mathrm{sec}^{-1}$. Curve $\mathrm{C} ; k_{+1}=5 \times 10^{4} \mathrm{M}^{-1} \mathrm{sec}^{-1}$.

Table 3. Effect of $k_{+1}$ value on time ratio.

\begin{tabular}{cc}
\hline$k_{+1}\left(\mathrm{M}^{-1} \mathrm{sec}^{-1}\right)$ & Time \\
\hline $5 \times 10^{6}$ & 85 \\
$5 \times 10^{5}$ & 57 \\
$5 \times 10^{4}$ & 0 \\
\hline
\end{tabular}

curve $\left(k_{+1}=5 \times 10^{4}, k_{-1}=5, K_{1}=10^{4}\right)$ in Fig. 7 and lower curve $\left(k_{+1}=5 x 10^{4}\right.$, $k_{-1}=0.5, K_{1}=10^{5}$ ) in Fig. 8 that parallel changes (the latter case) in the both rate constants with constant value of $K_{1}$ cause the time-course of $X_{2}(t)$ much closed to the steady-state pattern. This infers that the $K_{1}$ value has also some influence to the time-course o-f the amount of the enzyme-substrate complex.

\section{Rate constants at second step and steady-state}

Since both forward and reverse rate constants at the second step are the first-order constant different from those at the first step, the effects of the rate constants $k_{+2}$ and $k_{-2}$ and the equilibrium constant $K_{2}$ on the steady-state behavior seem to have rather simple fashion. Consequently, only the effect of reverse rate constant was examined. As shown in Fig. 9 and Table 5, ten times increase in the $k_{-2}$ value caused a small decrease in the steady-state periods. It should be noticed that a small value of $k_{-2}$ caused the elongation of the steady- 


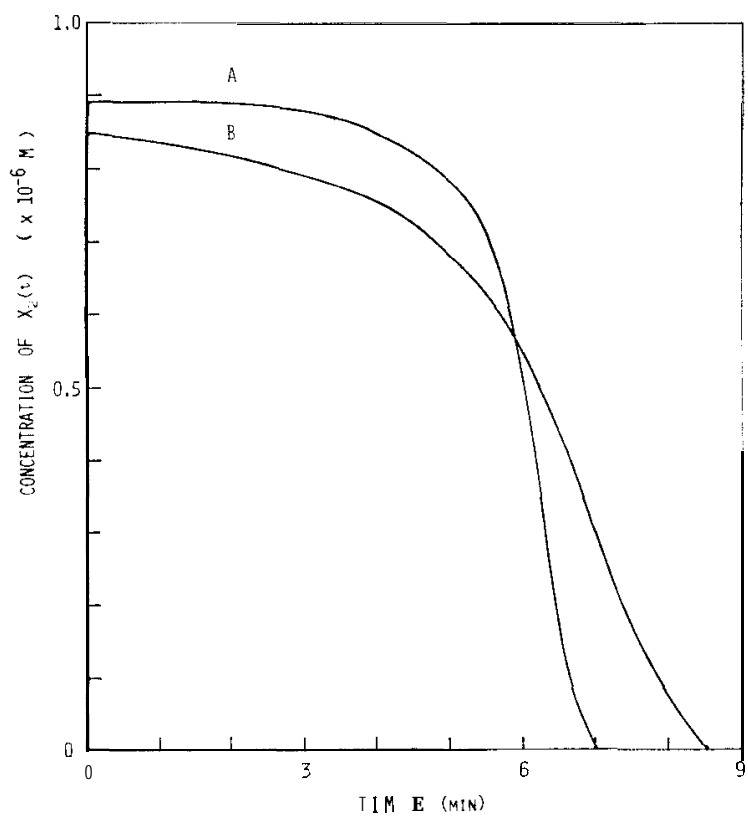

Fig. 8. Calculated time-course of $X_{2}(t)$ with changing the combination of $k_{+1}$ and $k_{-1}$ under fixing the value of the equilibrium constant. Curve A; $\mathrm{k}_{+1}=5 \times 10^{5} \mathrm{M}^{-1}$ $\mathrm{sec}^{-1}, k_{-1}=5 \mathrm{sec}^{-1}$. Curve B; $k_{+1}=5 \times 10^{4} \mathrm{M}^{-1} \mathrm{sec}^{-1}, k_{-1}-0.5 \mathrm{sec}^{-1}$. Other parameters are: $S(0) / E(0)=50, k_{2}=10^{3} \mathrm{sec}^{-1}, k_{-2}=10^{2} \mathrm{sec}^{-1}, k_{+3}=0.16 \mathrm{sec}^{-1}$.

Table 4. Influence of combination of $k_{1}$ and $k_{-1}$ on time ratio under fixing value of 4 .

\begin{tabular}{cccc}
\hline$k_{+1}\left(\mathrm{M}^{-1} \sec ^{-1}\right)$ & $k_{-1}\left(\mathrm{sec}^{-1}\right)$ & $\begin{array}{r}\text { Equilibrium } \\
\text { const. }\left(K_{1}\right)\end{array}$ & $\begin{array}{r}\text { Time ratio } \\
(\%)\end{array}$ \\
\hline $5 \times 10^{5}$ & 5 & $10^{5}$ & 57 \\
$5 \times 10^{4}$ & 0.5 & $10^{5}$ & 0 \\
\hline
\end{tabular}

state periods in contrast to the effects of other rate constants.

\section{Factors affecting steady-state behavior}

Summarized results of the simulation on the three-step enzymatic reaction are listed in Table 6. The most influential factor is the ratio of the initial concentration of substrate to that of enzyme. The ratio below 50 cannot establish the steady-state during enzymatic reactions, even if varied combination of the rate constants is adopted for simulation. The rate constants at the first step participating in the formation and the breakdown of ES, also play a role for the appearance of the steady-state. The rate constants at the second step influence only the extent of the time periods of the steady-state; if the $S(0) / E(0)$ ratio and the rate constants at the first step have sufficient value for the appearance of the steady-state, $k_{r_{2}}$ and $k_{-2}$ may show the elongation effect on the time of the steady-state. This consideration suggests that the behavior of the threestep enzymatic reaction with respect to the steady-state is essentially similar 


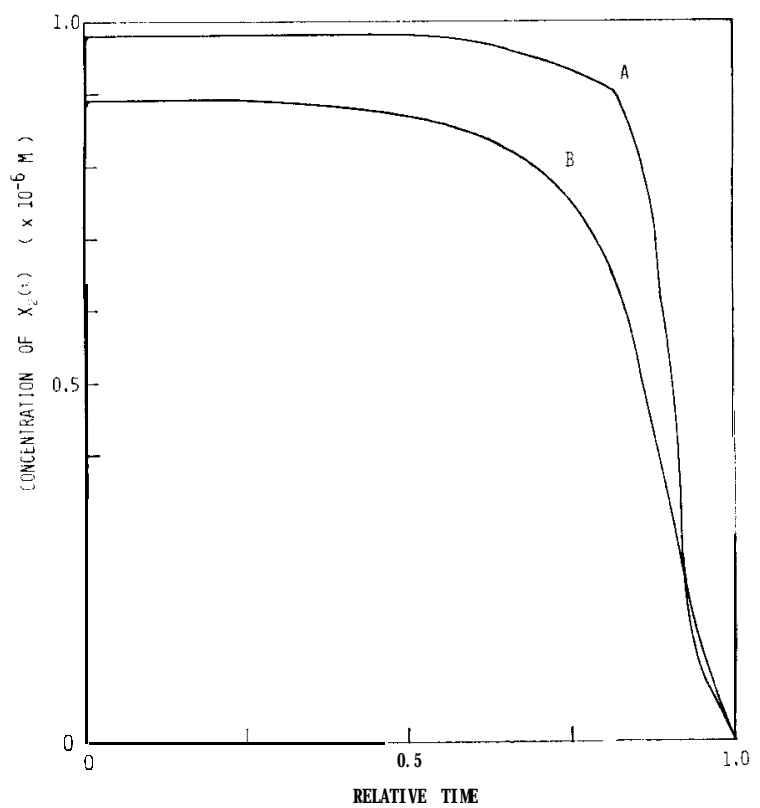

Fig. 9. Calculated time-course of $X_{2}(t)$ with changing the $k_{-2}$ value (time axis shows the relative scale). Curve A $; k_{-2}=10 \mathrm{sec}^{-1}$. Curve $\mathrm{B} ; k_{2}=10^{2} \mathrm{sec}^{-1}$. Other parameters are: $S(0) / E(0)=50, k_{1}=5 \times 10^{5} \mathrm{M}^{-1} \mathrm{sec}^{-1}, k_{1}=5 \mathrm{sec}^{1}, k_{\llcorner 3}=0.16 \mathrm{sec}^{-1}$.

Table 5. Effect of $k_{-2}$ value on time ratio.

\begin{tabular}{cc}
\hline$k-\left(\mathrm{sec}^{-1}\right)$ & Time ratio (\%) \\
\hline 10 & 57 \\
10 & 75
\end{tabular}

Table 6. Summarized results of simulation.

\begin{tabular}{|c|c|c|c|c|c|c|c|c|c|c|c|}
\hline$S(O) / E(O)$ & 100 & $100-10$ & $\begin{array}{rl}100 & -50 \\
5 & 50\end{array}$ & & 50 & 50 & 50 & 50 & 30 & 10 & 10 \\
\hline$k_{+1}\left(10^{5} \mathrm{M}^{-1} \mathrm{sec}^{-1}\right)$ & 1 & 5 & & 5 & & 0.5 & & 0.5 & 5 & 5 & 5 \\
\hline$k_{-1}\left(\sec ^{-1}\right)$ & 5 & 5 & 5 & & 5 & 5 & 5 & 0.5 & 5 & 5 & 5 \\
\hline$k_{+2}\left(10^{3} \sec ^{-1}\right)$ & 1 & 1 & 1 & 1 & 1 & 1 & 1 & 1 & 1 & 1. & 1 \\
\hline$k_{-2}\left(10^{2} \sec ^{-1}\right)$ & 1 & 1 & 1 & $\begin{array}{ll}1 & 1\end{array}$ & $1 \quad 0$ & 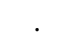 & $\begin{array}{ll}1 & 1\end{array}$ & 11 & 1 & 1 & 1 \\
\hline$k_{\mathrm{r} 3}\left(\sec ^{-1}\right)$ & 0.12 & 0.16 & Il. 20 & 0.16 & $\begin{array}{ll}6 & 0.16\end{array}$ & 0.16 & 0.16 & 0.10 & 0.16 & 0.16 & 0.03 \\
\hline Whole reaction (mimif) & 17 & 13 & 10 & 6.5 & 7 & 6 & 12 & 8.5 & 5 & 2.5 & 10 \\
\hline Steady-state time (min) & 12.5 & 9.5 & & .5 & 5.5 & 4 & 4.5 & () 0 & 0 & 0 & 0 \\
\hline Time ratio $(\%)$ & 74 & 73 & & 5 & 85 & 57 & 75 & 00 & 0 & 0 & ii \\
\hline$X_{26 t e a}$ sty-state $\left(10^{-6} \mathrm{M}\right)$ & 0.90 & 0.90 & 0.90 & 0.91 & 0.89 & 0.98 & 0 & 0 & 0 & 0 & 0 \\
\hline
\end{tabular}


to that of the two-step reaction (Michaelis-Menten scheme). The $k_{+3}$ which controls the rate of overall reaction does not change the profile of the time-course of $X_{2}(t)$. This may infer that when the original enzymatic reaction does not exhibit the steady-state periods, the appearance of the steady-state may not be expected by the artificial slow-down of the reaction with changing the milieu conditions such as reaction temperature.

\section{DISCUSSION}

Analog computer has been widely used for simulation of chemical reaction including enzymatic reactions because computation of rate equation can easily be performed. In most cases, however, simulation results were not represented by the real time-scale; the time-scale in the plotting of time-course has usually second units with the whole time range of order of several ten seconds. In another words, the computation has been performed by choosing suitable values of rate constants so that substrate was completely consumed within several ten seconds. The reason why such the computation has widely been performed is the difficulty of the real time computation by analog computer. Since enzymatic reactions are represented in nature by nonlinear differential equation, the judgement on the steady-state from the simulated results by simply replacing the calculated arbitrary time-scale to the real time-scale should be avoided. For exact simulation and following proper judgement, therefore, it is preferable that the computation is performed with the real time-scale. The rate equation of multi-step enzymatic reaction contains rate constants of various order, from $10^{-1}$ to $10^{7}$. The differential equation containing such a great difference in the values of rate parameters is not solved by usual analog computer, when the real time-scale is required.

In digital simulation, the great difference in the values of rate constants is not critical factor for the numerical computation of the rate equation. However, in practical computation, the steep gradients of $\mathrm{E}(\mathrm{t}), \mathrm{X},(\mathrm{t})$ and $X_{2}(t)$ at an early stage (see Fig. 2) caused an overflow at the operational register and the very small value of $\boldsymbol{E}(\boldsymbol{t})$ in following stages induced frequently the negative calculated value due to the computational error, suspending the flow of computation. To avoid such the obstructions, MRKGM program was adopted (see Fig. 1). The weak point of MRKGM is that the computational error with this program could not be predicted by the theoretical background. The amplitude of computational error with MRKGM must be estimated by comparing the computational results with those obtained by other programs. In comparison with the computational result obtained by HAMPCD program (FACOM SSL program, Hamming method), it was evidenced that computed values with MRKGM contain within $1 \%$ error. Thus, the computations with digital computer enabled the real-time simulation of the three-step enzymatic reaction.

In present study, the rate constants were assumed with referring to the experimentally obtained values on hydrolytic enzyme, lysozyme and chymotrypsin. Lysozyme catalyzes the cleavage of $\beta-1,4$-glucosaminide linkages of substrate larger than (NAG),. The $k_{+1}$ value is independent of the polymerization degree of substrate, being held at fixed value, whereas the $k_{-1}$ value is reversely pro- 
Table 7. Rate constants for enzyme-substrate complex (ES,) formation.

\begin{tabular}{|c|c|c|c|c|}
\hline Enzyme & Substrate & $k_{+1}\left(\mathrm{M}^{-1} \sec ^{-1}\right)$ & $k_{-1}\left(\sec ^{-1}\right)$ & Reference \\
\hline $\begin{array}{l}\text { Malate } \\
\text { dehydrogenase }\end{array}$ & NADH & $5 \times 10^{8}$ & 50 & $\begin{array}{l}\text { Czeriinski and } \\
\text { Schreck (1963) }\end{array}$ \\
\hline $\begin{array}{l}\text { Pyruvate } \\
\text { carboxylase-Mn' }{ }^{2+}\end{array}$ & Pyruvate & $4.5 \times 10^{6}$ & $2.1 \times 10^{4}$ & $\begin{array}{l}\text { Mildvan, Leigh } \\
\text { and Cohn (1967) }\end{array}$ \\
\hline Ribonuclease & $\begin{array}{l}\text { Cytidine } 2^{\prime}, 3^{\prime}- \\
\text { cyclic phosphate }\end{array}$ & $2-4 \times 10^{7}$ & $1-2 \times 10^{4}$ & $\begin{array}{l}\text { Erman and } \\
\text { Hammes (1966) }\end{array}$ \\
\hline \multirow[t]{2}{*}{ Lysozyme } & $\begin{array}{l}(\mathrm{NAG})_{2} \\
(\mathrm{NAG})\end{array}$ & $\begin{array}{l}4.6 \times 10^{6} \\
4.4 \times 10^{6}\end{array}$ & $\left.\begin{array}{l}9.5 \times 10^{2} \\
2.8 \times 10^{2}\end{array}\right\}$ & $\begin{array}{l}\text { Chipman and } \\
\text { Schimmel (1968) }\end{array}$ \\
\hline & $\begin{array}{l}\text { n-Methyl NAG } \\
\beta \text {-Methyl NAG }\end{array}$ & $\begin{array}{l}1.4 \pm 0.7 \times 10^{5} \\
1.6 \pm 0.8 \times 10^{5}\end{array}$ & $\left.\begin{array}{l}5.5 \pm 2.1 \times 10^{3} \\
4.5 \pm 1.7 \times 10^{3}\end{array}\right\}$ & Sykes (1969a) \\
\hline Chymotrypsin & $\begin{array}{l}\text { 3-Fluoro acetyl } \\
\text { 2-phenyl alanine }\end{array}$ & $1.0 \times 10^{4}$ & $4.9 \times 10^{2}$ & Sykes (1969b) \\
\hline
\end{tabular}

portional to the polymerization degree. Thus, in the present study, the $k_{.}{ }_{1}$ value was assumed to be 5 with considering the experimental finding that the binding constant of substrate (NAG) $)_{5}$ is of order of $10^{5}$. Several examples of rate constants participating in the formation of ES, are collected and listed in Table 7. The $k_{+1}$ and $k_{-1}$ values of hydrolytic enzymes are not always average. Both values are distributing to a wide range depending upon the combination of enzyme and substrate. The rate constants participating in the isomerization of the enzyme-substrate complex had been estimated experimentally for a few cases. Examples are shown in Tables 8 and 9 . Since the isomerization may be accompanying the some conformational change, a large value as much as the value of $k_{+1}$ will not be expected and the values adopted to the present simulation seem to be average of those of general enzymatic reactions.

Table 8. Rate constants for lysozyme-NAG complex isomerization.

\begin{tabular}{ccccc}
\hline Substrate & $\mathrm{pH}$ & $k_{+2}\left(\mathrm{sec}^{-1}\right)$ & $k_{-2}\left(\mathrm{sec}^{-1}\right)$ & Reference \\
\hline$(\mathrm{NAG})_{2}$ & $\mathbf{6 . 0}$ & $2 \times 10^{4}$ & $1 \times 10^{3}$ & Holler, \\
Rupley \\
$(\mathrm{NAG})_{2}$ & 7.0 & $1.5 \times 10^{4}$ & $2 \times 10^{3}$ & and Hess \\
$(\mathrm{NAG})_{3}$ & 7.0 & $\mathbf{4} \times 10^{2}$ & $\mathbf{5 0}$ & $(\mathbf{1 9 6 9 )}$ \\
\hline
\end{tabular}

Table 9. Rate constants for adenosine triphosphate-creatine phosphotransferase complex isomerization.

\begin{tabular}{cccc}
\hline$k_{+2}\left(\mathrm{sec}^{-1}\right)$ & $k_{-2}\left(\mathrm{sec}^{-1}\right)$ & $k-, / k+,(M)$ & Reference \\
\hline $1.67 \times 10^{4}$ & $2.4 \mathrm{X} 103$ & $6.0 \times 10^{-4}$ & $\begin{array}{c}\text { Hammes and } \\
\text { Hurst (1969) }\end{array}$ \\
\hline
\end{tabular}

As described above, the rate constants of enzymatic reactions distribute to wide range. The application of the results of the present study to design the experimental conditions for enzymatic reactions should be bounded to those reactions which contain the rate constants close to the values assumed in the present study. For the reactions that have quite different rate constants, the time-range 
where the steady-state approximation is permitted should be examined by another simulation.

\section{REFERENCES}

Chipman, D. M. and P. R. Schimmel 1968 Dynamics of Lysozyme-Saccharide Interactions. $J$. Biol. Chem., 243 :3771.-3774

Chipman, D. M. 1971 A Kinetic Analysis of Lysozyme with Oligosaccharides from Bacterial Cell Walls. Biochemistry, 10 : 1714-1722

Czerlinski, G. and G. Schreck 1964 Chemical Relaxation of the Reaction of Malate Dehydrogenase with Reduced Nicotinamide Adenine Dinucleotide Determined by Fluoroescence Detection. Biochemistry, $3: 89-100$

Erman, J. E. and G. G. Hammes 1966 Relaxation Spectra of Ribonuclease. IV. The Interaction of Ribonuclease with Cytidine 2' : 3'-Cyclic Phosphate. J. Amer. Chem. Soc., 88: 56075614

Hammes, G. G. and J. K. Hurst 1969 Relaxation Spectra of Adenosine Triphosphate-Creatine Phosphotransferase. Biochemistry, 8 : 1083-1094

Heineken, F. G., H. M. Tsuchiya and R. Aris 1967 a On the Mathematical Status of the Pseudo-steady State Hypothesis of Biochemical Kinetics. Math. Biosci., 1: 95-113

Heineken, F. G., H. M. Tsuchiya and R. Aris 1967b On the Accuracy of Determining Rate Constants in Enzymatic Reactions. Math. Biosci., 1: 115-141

Holler, E., J. A. Rupley and G. P. Hess 1969 Kinetics of Lysozyme-Substrate Interactions. Biochem. Biophys. Res. Commun., 37 : 423-429

Mildvan, A. S., J. S. Leigh and M. Cohn 1967 Kinetic and Magnetic Resonance Studies of Pyruvate Kinase III. The Enzyme-Metal-Phosphoryl Bridge Complex in the Fluorokinase Reaction. Biochemistry, $6: 1805-1818$

Sykes, B. D. 1969 a A Trasient Nuclear Magnetic Resonance Study of Kinetics of Methyl NAcetyl-D-glucosaminide Inhibition of Lysozyme. Biochemistry, 8 :1110-1116

Sykes, B. D. 1969 b An Application of Trasient Nuclear Magnetic Resonance Method to the Measurement of Biological Exchange Rates with the Chymotrypsins. J. Amer. Chem. Soc., 91: 949-955

Walter, C. F., M.F. Morales 1964 An Analogue Computer Investigation of Certain Issues in Enzyme Kinetics. J. Biol. Chem., 239: 1277-1283 